\title{
@®ङ $O$ lugar próprio no espaço impróprio: o negro, o judeu e o comum
}

\author{
Paulo Henrique Fernandes Silveira*
}

\begin{abstract}
Resumo: No pós-guerra, uma série de intelectuais que residiam na França, alguns deles, como exilados ou expatriados, travaram um intenso debate a respeito das condições do negro e do judeu. Jean-Paul Sartre formulou uma das questões centrais desse debate: haveria uma essência da negritude ou do judaísmo? Para Frantz Fanon, Maurice Blanchot, Jacques Derrida e Edmond Jabès, a negritude e o judaísmo podem ser compreendidos a partir das experiências do exílio e da expatriação. Esse artigo pretende reconstruir esse debate e analisar a importância do não-pertencimento para as concepções de comunidade e comum desenvolvidas por Jean-Luc Nancy, Giorgio Agamben e Jacques Rancière.
\end{abstract}

Palavras-chave: Negro. Judeu. Expatriação. Não-pertencimento. Comum.

\section{El lugar propio en el espacio impropio: el negro, el judío y el común}

Resumen: En la pos-guerra, una serie de intelectuales que vivían en Francia, algunos de ellos, como exilados o expatriados, trabaran un intenso debate a respecto de las condiciones del negro y del judío. Jean-Paul Sartre formuló una de las preguntas centrales de ese debate: ¿habría una esencia da negritud o de judaísmo? Para Frantz Fanon, Maurice Blanchot, Jacques Derrida y Edmond Jabès, la negritud y el judaísmo pueden ser comprendidos a partir de las experiencias de exilio y de la expatriación. Ese artículo pretende reconstruir ese debate y analizar la importancia del no-pertenencia a las conceptos de comunidad y común desarrolladas por Jean-Luc Nancy, Giorgio Agamben y Jacques Rancière.

Palabras-clave: Negro. Judío. Expatriación. No-pertenencia. Común.

\footnotetext{
* Doutor em Filosofia pela Universidade de São Paulo (USP). Professor da Faculdade de Educação da Universidade de São Paulo. E-mail: paulo.henrique.fernandes@usp.br ORCID: https://orcid.org/0000-0002-7065-0207
} 


\title{
The proper place in the improper space: the black, the jewish and the
} common

\begin{abstract}
In the postwar period, a number of intellectuals residing in France, some of them as exiles or expats, the intellectuals engaged in an intense debate about the conditions of the black and the jewish. Jean-Paul Sartre formulated one of the key questions of this debate: Is there an essence of blackness or judaism? For Frantz Fanon, Maurice Blanchot, Jacques Derrida, and Edmond Jabès, blackness and judaism can be understood from the experiences of exile and expatriation. This article aims to reconstruct this debate and analyze the importance of nonbelonging to the conceptions of community and common developed by Jean-Luc Nancy, Giorgio Agamben, and Jacques Rancière.
\end{abstract}

Keywords: Black. Jewish. Expatriation. Non-belonging. Common.

Meu lugar é no limiar

Edmond Jabès

\section{Introdução}

Talvez não seja um exagero afirmar que os debates sobre o antissemitismo e o colonialismo marcaram o pensamento francês do pósguerra. Nos anos de 1940 e 1950, o antissemitismo provocou a migração de uma série de intelectuais para a França. Após as leis de exceção implementadas na Argélia, no início dos anos 40, ainda criança, Jacques Derrida chega com sua família a Paris. Tendo passado por vários campos de concentração nazistas na Romênia, em 1948, Paul Celan decide morar na França. Em meados dos anos 40, depois de deixar um campo de trabalho forçado na Tunísia, Albert Memmi decide fixar-se em Paris. Também de origem judaica, em 1956, o egípcio Edmond Jabès exila-se na França. Entre as décadas de 1930 e 1960, os martiniqueses Aimé Cesaire e Frantz Fanon e o senegalês Léopold Senghor, publicam em Paris textos fundamentais contra o colonialismo. 
Os debates sobre o antissemitismo e sobre o colonialismo foram estimulados por alguns textos de Jean-Paul Sartre. Em 1946, Sartre escreve o ensaio "Reflexões sobre a questão judaica". Em 1948, o filósofo publica o "Orfeu Negro", texto de introdução para uma antologia de jovens poetas negros e malgaches, entre eles, os amigos de liceu, Aimé Cesaire e Léopold Senghor. Em 1957, Sartre faz a apresentação do livro: Retrato do colonizado, precedido do retrato do colonizador, de Albert Memmi. Em 1961, ele faz a apresentação do livro: Os condenados da terra, de Frantz Fanon. Esses e outros textos de Sartre sobre esse tema são republicados, em 1964, na coletânea: Situações V: Colonialismo e neocolonialismo.

\section{A questão do negro e a subjetivação}

No texto que publica alguns meses após o término da Segunda Guerra Mundial, Sartre distingue o judeu autêntico do judeu inautêntico. Para o filósofo, a autenticidade consiste em: "tomar consciência lúcida e verídica da situação, em assumir as responsabilidades e os riscos que tal situação comporta, em reivindicá-la no orgulho ou na humilhação, às vezes, no horror e no ódio" (SARTRE, 1965, p. 54). A questão judaica, portanto, refere-se ao modo autêntico ou inautêntico do judeu assumir sua condição de judeu no país em que é levado a viver.

A situação política dos judeus motiva Sartre a revisitar algumas ideias que, três anos antes, ele tinha desenvolvido no Ser e o nada. Com a ambição de fazer-se reconhecer como homem entre homens, o judeu inautêntico acaba por agir de má-fé: "mascara a si próprio a verdade que, no entanto, traz no fundo de si mesmo (SARTRE, 1965, p. 59). O judeu inautêntico é habitado pela consciência de ser judeu, mas se esforça para disfarçar todos os traços da sua personalidade, rompe os vínculos com sua comunidade e nega participar da realidade judaica (SARTRE, 1965, p. 64).

No "Orfeu negro", texto absolutamente elogioso sobre a literatura, o movimento da negritude e as aspirações revolucionárias dos jovens poetas negros, Sartre anota: "insultado, avassalado, reergue-se, apanha a palavra 'preto' que lhe atiram qual uma pedra; reivindica-se como negro, 
perante o branco, na altivez" (SARTRE, 1965, p. 98). O negro, afirma o filósofo, encontra-se encurralado na autenticidade:

Nesse caso não há escapatória, nem subterfúgios, nem "passagem de linha" a que possa recorrer; um judeu, branco entre os brancos, pode negar que seja judeu, declarar-se homem entre homens. O negro não pode negar que seja negro ou reclamar para si esta abstrata humanidade incolor: ele é preto (SARTRE, 1965, p. 98).

Esses ensaios de Sartre influenciaram os trabalhos de Frantz Fanon. É provável que o título do seu primeiro livro, Pele negra, máscaras brancas, publicado em 1952, seja uma referência à inevitável autenticidade do homem negro. Por outro lado, o livro critica o conceito e o movimento da negritude. Minha pele negra, reclama Fanon, "não é depositária de valores específicos" (2008, p. 188). Para o escritor, não existe algo como uma essência da negritude. A experiência negra é ambígua, sustenta Fanon, "pois não há um preto, há pretos" (2008, p. 123).

No livro Os condenados da terra, publicado em 1961, Fanon retoma sua crítica às posições defendidas pelos intelectuais do movimento da negritude. Para se contrapor à imagem negativa que o colonizador tenta impelir sobre o negro, argumenta Fanon, o movimento acabou forjando uma imagem sobre a essência da negritude: "À afirmação incondicional da cultura europeia sucedeu a afirmação incondicional da cultura africana (FANON, 1968, p. 177). Na análise de Deivison Faustino, para Fanon: “o ser humano é, antes de tudo, um ser que questiona, aberto à contingência histórica que precede a qualquer essência fixa" (2015, p. 85). Nesse sentido, Fanon defende uma outra perspectiva sobre a construção da identidade cultural dos negros: "O homem colonizado que escreve para seu povo, quando utiliza o passado, deve fazê-lo com o propósito de abrir o futuro, de convidar à ação, fundar a esperança" (1968, p. 193).

As críticas de Fanon ao movimento da negritude, encabeçado pelos intelectuais Aimé Cesaire e Léopold Senghor, apontam para a necessidade de uma transformação revolucionária da sociedade. Numa 
dessas críticas, Fanon vale-se de uma ideia que Sartre desenvolve no "Orfeu negro". Nas últimas linhas do seu ensaio, o filósofo assegura: "o impulso poético coincide com o impulso revolucionário" (SARTRE, 1965, p. 129). Em oposição à subjetividade encerrada na concepção da negritude do movimento, Fanon defende uma subjetividade que possa ser construída com poesia e revolução. Numa passagem do Pele negra, máscaras brancas, Fanon relembra alguns versos de Jacques Roumain que Sartre também havia citado:

África, eu guardei sua memória

África, você é em mim

como o espinho na ferida (...)

NO ENTANTO

eu só quero ser da sua raça

operários e camponeses de todos os países...

operário branco de Detroit, peão negro do Alabama

povo incalculável das galés capitalistas

o destino nos coloca ombro a ombro.

("Bois d'ébene", Prelúdio, citado por FANON, 2008, p. 122). ${ }^{1}$

\section{A questão mais profunda}

Apesar das suas relações políticas e ideológicas com o nazismo, algumas ideias de Heidegger contribuíram, nos anos 60, para o debate sobre a questão judaica. Em 1958, dois livros do filósofo são traduzidos e publicados na França: Introdução à metafísica e Ensaios e conferências. Nesses trabalhos, Heidegger discorre sobre o pensar e o questionar. A partir da análise dos fragmentos dos filósofos pré-socráticos e dos versos de alguns poetas alemães, o filósofo procura compreender as condições necessárias para o cultivo de pensamentos e de questionamentos profundos.

\footnotetext{
${ }^{1}$ Tradução livre dos versos: “Afrique j’ai gardé ta mémoire/ Afrique, tu es en moi/ comme l'écharde dans la blessure (...)/ POURTANT/ je ne veux être que de votre race/ ouvriers paysans de tous les pays.../...ouvrier blanc de Detroit péon noir d'Alabama/ peuple innombrable des galères capitalistes/ le destin nous dresse épaule contre épaule." (FANON, 1975, p. 109-110).
} 
Num desses livros, Heidegger relaciona a disposição para o pensamento com o verso de Hölderlin: "poeticamente o homem habita" (2006, p. 37). No ensaio: "Construir, habitar, pensar", o filósofo estabelece articulações entre: a construção de um lugar, o modo de habitar e o pensar mais profundo. $\mathrm{O}$ construir e o pensar pertencem ao habitar (HEIDEGGER, 2006, p. 140), e a poesia é a capacidade fundamental do homem habitar (HEIDEGGER, 2006, p. 179). No entanto, lamenta-se Heidegger, estamos numa época em que, normalmente, os homens habitam sem poesia e questionam sem profundidade.

Em meados dos anos 20, quando era estudante de alemão e de filosofia na Universidade de Estrasburgo, por indicação do amigo Emmanuel Levinas, o jovem Maurice Blanchot conhece o livro: Ser e tempo, de Heidegger (BIDENT, 1998, p. 44). Em 1946, Blanchot publica o ensaio “A palavra 'sagrada' de Hölderlin", seu primeiro estudo sobre o poeta alemão (1997). Nesse texto, Blanchot acompanha cuidadosamente as análises que Heidegger faz de Hölderlin.

No início dos anos 60, Blanchot publica o artigo: "A questão mais profunda" (2001). Ainda que passe pelo tema heideggeriano, nesse texto e em outros também incluídos na coletânea: A conversa infinita, Blanchot aproxima a figura do poeta que questiona o profundo à figura do judeu historicamente oprimido (BIDENT, 1998,p. 441). No ensaio "O indestrutível”, de 1962, uma análise do livro: A espécie humana, em que Robert Antelme descreve os horrores que enfrentou nos campos de concentração, Blanchot destaca o nomadismo presente na história dos judeus: "se o judaísmo está destinado a adquirir um sentido para nós, é sem dúvida mostrando-nos que é preciso, em qualquer tempo, estar pronto para pôr-se a caminho" (2007, p. 72).

\section{A questão do judeu e o não-pertencimento}

Num de seus artigos sobre a poesia de René Char, um dos seus grandes amigos, Blanchot percebe um estilhaçamento, um deslocamento, uma interrupção na linguagem fragmentada do poeta (2010, p. 45). Algo 
semelhante ao que ele também encontra nos versos de Paul Celan (BLANCHOT, 2011, p. 103) e de Edmond Jabès (BLANCHOT, 1971, p. 252). Como se esses poetas judeus narrassem um persistente nãopertencimento:

\begin{abstract}
Pensemos na expatriação. A expatriação não significa apenas a perda do país, mas um modo mais autêntico de residir, de habitar sem hábito; o exílio é a afirmação de uma nova relação com o Exterior. Assim, o poema fragmentado não é um poema inacabado, mas que se abre a outro modo de acabamento, aquele que está em jogo na espera, no questionamento ou em alguma afirmação irredutível à unidade. (BLANCHOT, 2010, p. 42).
\end{abstract}

Esses textos que Blanchot escreve no início dos anos 60 influenciam a poesia de Jabès que, em 1962, envia-lhe o manuscrito do: Livro das questões (BOUNOURE, 1984, p. 34). A partir desse livro, publicado em 1963, os poemas de Jabès passam a destacar a importância dos questionamentos profundos, a situação do refugiado que busca se encontrar noutro lugar e sua relação com a tradição judaica. Num livro em que trata da condição do estrangeiro, Jabès escreve:

Deixei uma terra que não era a minha por outra que também não é.

Refugiei-me num vocábulo de tinta, tendo o livro por espaço; palavra de lugar algum. (1989, p. 107). ${ }^{2}$

Um pouco como faz Blanchot, que depreende do nomadismo histórico dos judeus uma perspectiva sobre o homem em geral, Jabès retira da sua própria experiência, a posição de um poeta qualquer frente à linguagem. No Livro das questões, Jabès afirma acreditar na missão do escritor: "Ele a recebe do verbo que traz consigo seu sofrimento e sua

\footnotetext{
${ }^{2}$ Tradução livre dos versos: “J'ai quitté une terre qui n'était pas la mienne,/ pour une autre qui, non plus, ne l'est pas./ Je me suis réfugié dans un vocable d'encre, ayant le livre pour/ espace; parole de nulle part." (JABÈS, 1989, p. 107).
} 
esperança. Ele interroga as palavras que o interrogam, ele acompanha as palavras que o acompanham" (1963, p. 64). Para aqueles que estão à procura, aconselha Jabès: "uma folha branca está repleta de caminhos" (1963, p. 55).

$\mathrm{Na}$ bela interpretação que Derrida faz da poesia de Jabès, num dos ensaios do livro: A Escritura e a diferença, de 1967, o filósofo percebe três presenças da ausência em seus versos: a ausência que ancora cada pergunta, a ausência de um lugar e a ausência do próprio autor. Aquele que interroga passa a palavra a outro e exime-se de oferecer todas as respostas. Isso é o oposto, afirma Blanchot, dos terríveis monólogos de Hitler (2001, p. 131). A ausência de lugar, destaca Derrida, é o título de um poema de Jabès, mas ela também está presente na imagem do deserto, recorrente em seus versos (1971, p. 60). A ausência do autor, afirma o filósofo, está presente no momento em que as palavras caminham sozinhas, livres e emancipadas (DERRIDA, 1971, p. 61).

No limite dessa poética da ausência, analisa Derrida, o poeta sacrifica sua existência pela palavra (1971, p. 62). O autor retira-se do mundo para ganhar lugar na folha branca do livro. Assim como Fernando Pessoa, Albert Camus e Caetano Veloso, Jabès também procura o exílio na pátria da sua língua (1989, p. 97). De sua experiência como expatriado, o poeta engendra uma poesia da diáspora, ou melhor, ele faz da poesia a sua forma de habitar a diáspora:

Dois países dividem minha alma.

O primeiro - aquele de onde venho - fala-me da minha ausência originária.

$\mathrm{O}$ segundo - em direção ao qual eu fui - habitua-me à página virada de onde minha palavra irromperá.

A língua tem por lugar, a língua.

O exílio da língua é a condição do exilado. (JABÈS, 1989, p. 97). ${ }^{3}$

\footnotetext{
${ }^{3}$ Tradução livre dos versos: "Deux pays se partagent mon âme./ Le premier - celui d'où je viens - me parle de mon originaire absence. Le second - celui vers lequel je suis allé m'accoutume à la page tournée d'où ma parole poindra. La langue a pour lieu, la langue. L'exil de la langue est la condition de l'exilé." (JABÈS, 1989, p. 97).
} 
Num poema tardio, Jabès sugere que sua ausência em todo e qualquer lugar do mundo ressalta sua presença para si mesmo; uma presença a cada dia mais ciente da sua própria ausência (1993, p. 7). Nos versos que Jabès dedica ao tema, essa ausência para si não significa a perda de uma subjetividade, tampouco esses versos apontam para a procura de uma subjetividade definida e acabada que possa ser encontrada ou construída em algum lugar. Essa ausência para si não traduz uma potência a ser realizada. $\mathrm{O}$ poeta parece tomar a folha branca do livro e a liberdade das palavras emancipadas como referências para um processo de subjetivação. Num de seus poemas, Jabès se reconhece no próprio movimento em que procura a si mesmo:

\author{
Estou à procura \\ de um homem que não conheço, \\ que nunca foi tão eu mesmo \\ como desde que o procuro. $\left(1990\right.$, p. 46). ${ }^{4}$
}

Nos anos 80, numa longa entrevista a Marcel Cohen, publicada com o título: Do deserto ao livro, Jabès analisa a relação do seu trabalho com a tradição judaica. No Livro das questões, o poeta já tinha indicado que o seu judaísmo não o forçava a rezar todos os dias e frequentar sinagogas (1963, p. 67).

Interpelado por Cohen sobre sua forma de compreender o judaísmo, Jabès reponde ter retomado a tradição a partir dos seus estudos sobre o Talmud e a Cabala (2000, p. 72). Segundo Jabès, por ser composto de interrogações, o Talmud é o livro do exílio, pois ele se refugia no lugar da pergunta, mas permanece distante das respostas (2000, p. 97).

É essa tradição, que vem do seu pai, e do pai do seu pai, que marca sua poesia (2000, p. 99). Por outro lado, afirma Jabès, seus poemas partem de uma ruptura que estaria no cerne do judaísmo: o Deus judaico quis estar ausente, por isso se calou (2000, p. 84). Suas questões se desenvolvem a partir dessa ruptura. Os rabinos, analisa o poeta, são intérpretes do livro:

\footnotetext{
${ }^{4}$ Tradução livre dos versos: "Je suis à la recherche/ d'un homme que je ne connais pas,/ qui jamais ne fut tant moi-même/ que depuis que je le cherche." (JABËS, 1990, p. 46).
} 
"para eles, encontrar a Deus é encontrar no livro a palavra que se oculta atrás da palavra" (2000, p. 71). De modo semelhante, as questões dos poemas de Jabès parecem sempre ocultar outras questões. A essa ruptura advinda da tradição, o poeta acrescenta a ruptura histórica provocada por Auschwitz:

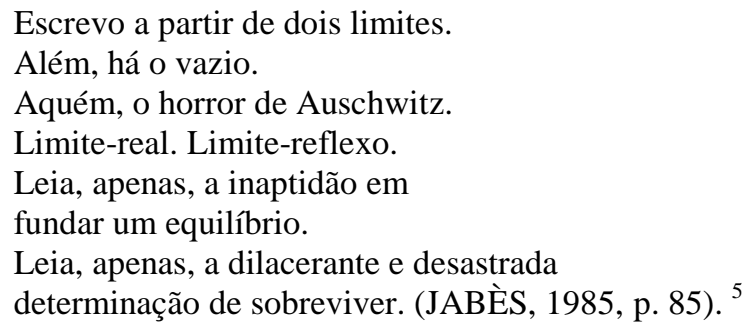

A condição de exilado, a ferida aberta pela Shoah e essa concepção do judaísmo atrelada à ruptura, fazem Jabès compreender-se como um desenraizado (2000, p. 89). Sobre esse tema, reconhece o poeta: "Tenho a impressão de só existir fora de todo e qualquer pertencimento. Esse não-pertencimento é minha própria substância" (JABĖS, 2000, p. 52). É a partir desse não-pertencimento que Jabès sente a necessidade de escrever (2000, p. 74). Seus livros dão testemunho desse nãopertencimento.

\section{O inacabamento e o comum}

Num rico diálogo com Blanchot, diálogo que se transformaria, nos anos 80 e 90, num grande debate, com a participação de outros autores, como Agamben e Rancière, o filósofo Jean-Luc Nancy retoma a questão da interrupção na linguagem fragmentada. ${ }^{6}$ Todavia, Nancy não trata

\footnotetext{
${ }^{5}$ Tradução livre dos versos: "J'écris à partir de deux limites./ Au-delà il y a le vide./ En deçà, l'horreur d'Auschwitz./ Limite-réelle. Limite-reflet./ $\mathrm{Ne}$ lisez que l'inaptitude à fonder un équilibre./ $\mathrm{Ne}$ lisez que la déchirante et maladroite/ détermination de suivivre." (JABÈS, 1985, p. 85).

${ }^{6}$ Em 1983, Nancy publica o artigo "A comunidade inoperada" na revista Aléa, republicado em livro com o mesmo título. Nesse texto, Nancy refere-se ao conceito de inoperância ou
} 
desse tema, apenas, no âmbito da literatura, mas também numa reflexão política sobre a comunidade:

A comunidade tem necessariamente lugar no que Blanchot nomeou de inoperância. Aquém ou além da obra, o que se retira da obra, o que não tem mais a ver, nem com a produção, nem com o acabamento, mas que encontra a interrupção, a fragmentação, o suspenso. A comunidade é feita da interrupção das singularidades, ou do suspenso que são as singularidades. (2016, p. 63).

No mesmo texto, algumas páginas adiante, Nancy relembra o testemunho sofrido de Antelme sobre sua experiência nos campos de concentração. Naquele espaço, a comunidade foi tomada como a última forma de resistência, aquilo que os algozes não conseguiram retirar dos prisioneiros, o que não pôde ser destruído (2016, p. 68). No ensaio: "O indestrutível”, Blanchot traz à tona, provavelmente, pela primeira vez, a discussão sobre "a relação nua com a vida nua" (2007, p. 83). Mesmo conduzidos à extrema indigência da necessidade, Antelme e alguns dos seus companheiros dos campos de concentração preservam o apego à vida e à exigência comum de resguardar os traços das relações coletivas (2007, p. 81). Quanto mais os algozes dos campos tentam reduzir os prisioneiros à indistinção, afirma Antelme, "mais nossa comunidade inclui de fato distinções, e mais essas distinções são rigorosas" (2011, p. 98).

Como bem analisa Pedro Hussak, ao destacarem a inoperância, a desocupação ou a ociosidade (désoeuvrement) como parte da comunidade, Blanchot e Nancy apontam para o inacabamento e a incompletude "que já não pode mais comportar uma identidade fixa em sua constituição" (2010, p. 2). Trata-se, afirma Nancy, de pensar na comunidade para além das obras sociais, econômicas, técnicas ou institucionais (2016, p. 63). Como na resistência daqueles que sobreviveram aos campos, uma comunidade que ainda sustente "a vida em comum” (HUSSAK, 2010, p. 2). Nas

ociosidade (désoeuvrement), que Blanchot analisa no ensaio "A experiência-limite". No mesmo ano, Blanchot continua o diálogo sobre o tema com o livro A comunidade inconfessável. 
palavras de Nancy, a comunidade não é uma obra a se fazer, ela é um dom a se renovar, a comunicar, ela é uma tarefa infinita e uma luta (2016, p. $69)$.

Em 1990, com a publicação do livro A comunidade que vem, Agamben entra nesse debate. Logo nas primeiras páginas do seu trabalho, o filósofo analisa o conceito de singularidade, um conceito que Nancy também discute em suas reflexões sobre a comunidade inoperante. Segundo Agamben, o ser que vem e que ajudará a formar a comunidade que virá, é um ser qualquer (2013, p. 10). A singularidade desse qualquer, explica o filósofo, é indiferente em relação a uma propriedade comum. Nesses termos, sua singularidade independe dele ter esta ou aquela propriedade que justifique o seu pertencimento a este ou aquele conjunto (2013, p. 10). A rigor, seria possível pensar numa singularidade alheia a qualquer laço de pertencimento (2013, p. 78).

$\mathrm{Na}$ formulação de Nancy, "a comunidade é feita da interrupção das singularidades” (2016, p. 63). Nesse sentido, é a partir de um acontecimento, de uma tomada da palavra ou da reivindicação de uma singularidade, que a comunidade passa por uma interrupção. Essa interrupção ou ruptura questiona o acabamento que a comunidade tenta forjar de tempos em tempos, ou melhor, que ela tenta forjar a todo momento. O inacabamento, argumenta Nancy, é o princípio que rege a comunidade: "no sentido onde seria preciso apreender o inacabável como um termo ativo, designando não a insuficiência ou a falta, mas a atividade de partilha, a dinâmica" (2016, p. 63).

Não se trata, portanto, de criar, de produzir ou de instalar uma nova comunidade, mas de fazê-la retomar a dinâmica que interrompa "o acabamento da sua partilha" (NANCY, 2016, p. 63). É nesse sentido que a ruptura demanda, como afirma Agamben, a singularidade de um qualquer, um qualquer que não se define por uma propriedade que justifique o seu pertencimento a um determinado conjunto da comunidade, mas, ao contrário, um qualquer que exija o seu direito de pertencimento a partir da sua própria condição de expropriado. De certo modo, essa ideia também aparece no texto que Blanchot dedica a Antelme: 
(...) é necessário que (...) o destituído seja não apenas acolhido como "outrem" na justiça da fala, mas recolocado na luta dialética, a fim de que também ele possa considerar-se novamente como um poder, o poder que detém o homem de necessidade e, finalmente, o "proletário". (...) Sim, e é o que exprime o livro de Antelme de maneira explícita em várias páginas que deveriam ser citadas. (2007, p. 85).

Alinhavando as questões sustentadas por esses autores, e acrescentando suas próprias questões e posições, em 1995, com a publicação do livro $O$ desentendimento, Rancière também entra nesse debate. Para explicar a comunidade que se acaba ou se fecha numa determinada partilha, o filósofo emprega o conceito de polícia, não no sentido das forças da ordem responsáveis pelos golpes de cassetete, mas no sentido amplo da manutenção de uma determinada distribuição dos lugares e das funções: "A polícia é, na sua essência, a lei, geralmente implícita, que define a parte ou a ausência de parte das "partes"' (2018, p. 43). Além disso, afirma Rancière, a polícia estabelece "uma ordem dos corpos que define as partilhas entre os modos do fazer, os modos de ser e os modos de dizer" (2018, p. 43). Em contraposição a essa polícia, o filósofo destaca a importância da atividade política, como sendo aquela capaz de promover uma ruptura na distribuição dos lugares e das funções:

A atividade política é a que desloca um corpo do lugar que lhe era designado ou muda a destinação de um lugar; ela faz ver o que não cabia ser visto, faz ouvir um discurso ali onde só tinha lugar o ruído, faz ouvir como discurso o que só era ouvido como ruído. (RANCIÈRE, 2018, p. 43).

É nesse contexto que Rancière analisa o episódio histórico da tomada da palavra, em 1832, pelo revolucionário Auguste Blanqui. Em resposta a um policial que o inquiria sobre sua profissão, Blanqui afirma ser "proletário". Ao ser objetado que essa não era uma profissão, o revolucionário argumenta que essa "é a profissão de trinta milhões de 
franceses que vivem de seu trabalho e que são privados de seus direitos políticos" (RANCIÈRE, 2018, p. 51). Segundo Rancière, essa fala de Blanqui traz à cena uma comunidade do dano que, ao exigir da comunidade política uma lógica igualitária, separa-se da comunidade policial (2018, p. 151). Nesse sentido, sustenta o filósofo, a atividade política implica na permanente reconstrução do comum a partir do conflito aberto por essas diferentes comunidades.

\section{Considerações finais}

Após a Segunda Guerra Mundial, ao receber uma série de intelectuais e artistas na condição de exilados ou de refugiados, a França se tornou um importante espaço para os debates sobre o antissemitismo e o colonialismo. Alguns ensaios de Sartre, entre eles,

"Reflexões sobre a questão judaica", de 1946, e "Orfeu Negro", de 1948, ajudaram a nortear esses debates. Nos anos 60, destacaram-se as posições de Fanon, contrárias à sustentação de uma essência da subjetividade do negro, e as posições de Jabès, contrárias à sustentação de uma essência da subjetividade do judeu. Esses autores também contribuíram para o debate sobre a possibilidade de sociedades construídas por imigrantes desenraizados. Nos anos 80, a partir dos trabalhos de Blanchot e de Nancy, os conceitos de expatriação, de inacabamento e de vida nua, bem como os testemunhos de Antelme sobre suas experiências nos campos de concentração nazistas, influenciaram o debate sobre as formas de comunidade. Esses debates que ocorreram no pós-guerra se aproximaram ao refletirem sobre três perspectivas essencialistas: sobre a subjetividade, sobre a sociedade e sobre o comum. O encadeamento desses debates nos permite destacar algumas questões importantes.

A partir desse encadeamento, podemos aferir que o debate travado entre Nancy, Rancière e Agamben sobre o comum está diretamente articulado ao debate sobre os horrores dos campos de concentração. Ao analisarem os testemunhos de Antelme em sua luta pela sobrevivência nos campos, Blanchot e Nancy concebem e desenvolvem o conceito de vida 
nua como sendo uma das indicações do limite último da manutenção de uma comunidade. Mais do que promover uma homenagem a Antelme e aos sobreviventes da barbárie, esse debate sobre sua experiência sofrida de resistência abre um caminho de reflexão sobre as possibilidades do comum e da comunidade.

A outra abordagem conceitual realçada por esse encadeamento de debates diz respeito à condição dos refugiados e dos expatriados. As experiências do exílio narradas por escritores negros e judeus estimulam o debate sobre as formas de criar um lugar próprio num espaço impróprio. Nas reflexões de Fanon, Jabès, Blanchot e Derrida sobre esse tema, a violência da exclusão incita a criação de uma nova possibilidade de estar e de habitar o mundo. A poesia, o pensamento e o diálogo mostram-se fundamentais para o ininterrupto e incansável combate da humanidade contra a barbárie.

\section{Referências}

AGAMBEN, G. A comunidade que vem. Belo Horizonte: Autêntica, 2013.

ANTELME, R. L'espèce humaine. Paris: Gallimard, 2011.

BIDENT. C. Maurice Blanchot: partenaire invisible: essai biographique. Paris: Éditions Champ Vallon, 1998.

BOUNOURE, G. Edmond Jabès: la demeure et le livre. Montpellier: Fata Morgana, 1984.

BLANCHOT, M. A conversa infinita - 1: a palavra plural. São Paulo: Escuta, 2001.

BLANCHOT, M. A conversa infinita - 2: a experiência limite. São Paulo: Escuta, 2007.

BLANCHOT, M. A conversa infinita - 3: a ausência do livro. São Paulo: Escuta, 2010. 
BLANCHOT. L'amitié. Paris: Gallimard, 1971.

BLANCHOT, M. Uma voz vinda de outro lugar. Rio de Janeiro: Rocco, 2011.

DERRIDA, J. A escritura e a diferença. São Paulo: Perspectiva, 1971.

FANON, F. Os condenados da terra. 1968. Rio de Janeiro: Civilização Brasileira, 1968.

FANON, F. Peau noire, masques blancs. Paris: Éditions du Seuil, 1975.

FANON, F. Pele negra, máscaras brancas. Salvador: EDUFBA, 2008. https://doi.org/10.7476/9788523212148

FAUSTINO, D. Por que Fanon, por que agora?: Frantz Fanon e os fanonismos no Brasil. 2015. 260f. Tese. (Doutorado em Sociologia) Centro de Educação e Ciências Humanas da Universidade Federal de São Carlos, São Carlos, 2015. Disponível em: https://repositorio.ufscar.br/handle/ufscar/7123. Acesso em: 25/09/2019.

HEIDEGGER, M. Ensaios e conferências. Petrópolis: Vozes; Bragança Paulista: Editora Universitária São Francisco, 2006.

HUSSAK, P. Sobre a comunidade que vem de Giorgio Agamben. In: Ética e alteridade. 2010. Disponível em: http://www.ufrrj.br/graduacao/prodocencia/ publicacoes/eticaalteridade/artigos/Pedro_Hussak.pdf. Acesso em: 25/09/2019.

JABÈS, E. Cela a eu lieu. Paris: Fourbis, 1993.

JABÈS, E. Del desierto al libro. Entrevista con Marcel Cohen. Madrid: Editorial Trotta, 2000.

JABÈS, E. Le livre des questions. Paris: Gallimard, 1963.

JABÈS, E. Le parcours. Paris: Gallimard, 1985. 
JABÈS, E. Le seuil; Le sable: Poésies complètes, 1943-1988. Paris: Gallimard, 1990.

JABÈS, E. Un étranger avec, sous le bras, un livre de petit format. Paris: Gallimard, 1989.

MATOS, O. Derrida: da razão pura à razão marrana. Psicologia, USP, v. 27, n. 2, p. 255-262, 2016. https://doi.org/10.1590/0103-6564A20162702

NANCY, J-L. A comunidade inoperada. Rio de Janeiro: 7 Letras, 2016.

RANCIÈRE, J. O desentendimento. São Paulo: Editora 34, 2018.

SARTRE, J-P. Reflexões sobre o racismo. São Paulo: Difusão Européia do Livro, 1965.

Data de registro: $11 / 12 / 2019$

Data de aceite: $26 / 08 / 2020$ 